\title{
Defense-Like Behaviors Evoked by Pharmacological Disinhibition of the Superior Colliculus in the Primate
}

\author{
Jacqueline T. DesJardin, ${ }^{1}$ Angela L. Holmes, ${ }^{1,2}$ Patrick A. Forcelli, ${ }^{1,2}$ Claire E. Cole, ${ }^{1}$ John T. Gale, ${ }^{1}$ Laurie L. Wellman, ${ }^{1,2}$ \\ Karen Gale, ${ }^{1,2}$ and Ludise Malkova ${ }^{1,2}$ \\ ${ }^{1}$ Department of Pharmacology and Physiology and ${ }^{2}$ The Interdisciplinary Program in Neuroscience, Georgetown University Medical Center, Washington, \\ DC 20007
}

\begin{abstract}
Stimulation of the intermediate and deep layers of superior colliculus (DLSC) in rodents evokes both orienting/pursuit (approach) and avoidance/flight (defense) responses (Dean et al., 1989). These two classes of response are subserved by distinct output projections associated with lateral (approach) and medial (defense) DLSC (Comoli et al., 2012). In non-human primates, DLSC has been examined only with respect to orienting/approach behaviors, especially eye movements, and defense-like behaviors have not been reported. Here we examined the profile of behavioral responses evoked by activation of DLSC by unilateral intracerebral infusions of the $\mathrm{GABA}_{\mathrm{A}}$ receptor antagonist, bicuculline methiodide (BIC), in nine freely moving macaques. Across animals, the most consistently evoked behavior was cowering (all animals), followed by increased vocalization and escape-like behaviors (seven animals), and attack of objects (three animals). The effects of BIC were dose-dependent within the range 2.5-14 nmol (threshold dose of $4.6 \mathrm{nmol}$ ). The behaviors and their latencies to onset did not vary across different infusion sites within DLSC. Cowering and escape-like behaviors resembled the defense-like responses reported after DLSC stimulation in rats, but in the macaques these responses were evoked from both medial and lateral sites within DLSC. Our findings are unexpected in the context of an earlier theoretical perspective (Dean et al., 1989) that emphasized a preferential role of the primate DLSC for approach rather than defensive responses. Our data provide the first evidence for induction of defense-like behaviors by activation of DLSC in monkeys, suggesting that the role of DLSC in responding to threats is conserved across species.
\end{abstract}

\section{Introduction}

The deep and intermediate layers of the superior colliculus (DLSC) integrate multimodal sensory information about environmental stimuli to allow for rapid reflex-like responses to potential threats (Stein et al., 2009). DLSC functions in a larger network that includes the periaqueductal gray (PAG), inferior colliculus (IC), amygdala, and hypothalamus. This network has been well characterized in rodents, and has been referred to as the "brain aversion system." Activation of this network can evoke defense-like behaviors (e.g., freezing, cringing, cowering and escape) as well as increased sympathetic arousal (e.g., increase in

Received June 19, 2012; revised Oct. 11, 2012; accepted Nov. 1, 2012.

Author contributions: K.G. and L.M. designed research; J.T.D., A.L.H., P.A.F., J.T.G., C.E.C., L.L.W., and L.M. performed research; J.T.D., A.L.H., P.A.F., J.T.G., C.E.C., K.G., and L.M. analyzed data; J.T.D., A.L.H., P.A.F., K.G., and L.M. wrote the paper.

The research was supported by NIH Grants R01MH82364 (L.M.), R21HD039937 (L.M.), R01NS020576 (K.G.), F31NS061623 (A.L.H.), and T32HD007459 (J.T.G.), the Howard Hughes Medical Institute Undergraduate Research Program (J.T.D.), and Autism Speaks (L.M.). We thank Carrie Silver, Guisou Zarbalian, Menna Teffera, Celeste Wallenta, Jadig Garcia, and Sandra Lopez for technical assistance.

The authors declare no competing financial interests.

Correspondence should be addressed to Dr. Ludise Malkova, Department of Pharmacology, Georgetown University Medical Center, 3900 Reservoir Rd. NW, Washington, DC 20007. E-mail: malkoval@georgetown.edu.

J. T. Gale's present address: Department of Neuroscience and the Center for Neurological Restoration at the Cleveland Clinic, Cleveland, OH 44195.

L. L. Wellman's present address: Department of Pathology and Anatomy, Eastern Virginia Medical School, Norfolk, VA 23501.

DOI:10.1523/JNEUROSCI.2924-12.2013

Copyright $\odot 2013$ the authors $\quad 0270-6474 / 13 / 330150-06 \$ 15.00 / 0$ blood pressure, heart rate, and respiration) (Brandão et al., 1994). Unilateral blockade of GABA receptors, glutamate infusion, or electrical stimulation within DLSC have evoked freezing, suppression of orienting to neutral stimuli of various modalities, exaggerated startle, defensive posture, violent jumping, and biting (Redgrave et al., 1981; Sahibzada et al., 1986). Electrical stimulation intensities below those that produce defense-like responses have evoked orienting responses of the head and eyes (McHaffie and Stein, 1982). These studies led to the conclusion that DLSC-evoked responses can be categorized into two classes: (1) orienting/pursuit (approach) and (2) avoidance/flight (defense). Anatomical evidence from rats suggests that these two systems are subserved by different regions within DLSC and depend on distinct output projections (Dean et al.,1989). These classes of response are also modulated by segregated anatomical inputs to DLSC corresponding to the visual fields associated with predator (defense) versus prey (pursuit) (Comoli et al., 2012).

In the primate, DLSC has been examined with respect to only one class of response: orienting/approach behaviors (Wurtz and Albano, 1980; Anderson and Rees, 2011; Gandhi and Katnani, 2011). Electrical or pharmacological stimulation of this region in monkeys results in contralaterally directed orienting of the head and eyes (Hikosaka and Wurtz, 1985; Cowie and Robinson, 1994), similar to that seen in rodents. However, a role for DLSC in defense-like behaviors in the non-human primate has never been documented. 
In the course of examining the effects of pharmacological activation of DLSC in non-human primates to identify the role of nigrotectal pathways in motor control, we observed the emergence of defense-like behaviors (Holmes et al., 2012). These observations, while reminiscent of the effects obtained in rodents, were unexpected. Based on the perspective of Dean et al. (1989), DLSC in non-human primates preferentially functions to facilitate orienting (approach) rather than defensive (avoidance) responses because animals, such as monkeys, "with relatively developed central vision and few predators...., have more to gain. ... from an orienting response." (Dean et al., 1989, p. 146). This view was prompted by the fact that no defense-like behaviors had been previously reported in monkey studies exploring DLSC.

Thus, here we examined the profile of behavioral responses to intracollicular infusion of the $\mathrm{GABA}_{\mathrm{A}}$ receptor antagonist, bicuculline methiodide (BIC), and determined the dose and site dependence of the behavioral responses. Our data provide the first evidence for induction of defense-like behaviors by activation of DLSC in monkeys, and suggest that the role of DLSC in responding to threats is conserved across species.

\section{Materials and Methods}

Subjects. Five pigtail macaques (Macaca nemestrina), one female (BR) and four males ( $\mathrm{ZH}, \mathrm{RK}, \mathrm{GW}$, and $\mathrm{OK})$, and four rhesus macaques (Macaca mulatta), one female (ST) and three males (DA, OL, and DE), were used in this study. Four of them (ST, DA, OL, and DE) were also used in a previous study on the interaction between DLSC and substantia nigra in motor control (Holmes et al., 2012). The monkeys were 2-5 years of age and weighed $3.2-7.0 \mathrm{~kg}$ at the beginning of this study. The study was approved by the Georgetown University Animal Care and Use Committee in accordance with the Guide for Care and Use of Laboratory Animals.

Infusion chamber and site verification. Each animal was implanted with a stereotaxically positioned chronic infusion chamber as previously described (West et al., 2011). For drug infusions, a grid was inserted in the chamber to provide guiding channels for the placement of an injector (Wellman et al., 2005) and a removable cannula. The grid allowed for infusions to be positioned $2 \mathrm{~mm}$ apart in the mediolateral and anteroposterior directions. To verify infusion-site location, each monkey received at least one T1-weighted MRI scan as described in West et al. (2011). Tungsten microelectrodes, visible on MR images, were inserted into the specified locations with the tip placed at $\sim 10 \mathrm{~mm}$ above the intended site. The position of the electrode tip on the scan was used to adjust the location of the infusion site as needed. Histology was performed for four animals (ZH, RK, GW, and DE) as previously described (Holmes et al., 2012). For the remaining animals, the cannula placement was determined from MRI.

Intracerebral drug infusions. To disinhibit DLSC, BIC was infused as outlined in Figure 1A. We found previously that unilateral infusions of BIC produced a robust effect, making it unnecessary to perform bilateral manipulations (Dybdal et al., 2012). Thus, we targeted unilateral infusions at both hemispheres in different experimental sessions.

The drug (as a sterile $10 \mathrm{~mm}$ solution) was infused in volumes of $0.25-1.4 \mu \mathrm{l}(2.5-14 \mathrm{nmol})$ at a $0.2 \mu \mathrm{l} / \mathrm{min}$ rate under aseptic conditions as previously described (West et al., 2011). The entire infusion procedure lasted 10-15 min. At least $48 \mathrm{~h}$ were allowed to elapse between drug treatments in an individual subject. Doses were titrated for each animal to reach a dose sufficient to produce a response. Control infusions (equal volumes of sterile saline) were performed in sites from which defenselike behaviors were evoked.

$M R I$ verification of tissue volume reached by infusion. To verify the volume of diffusion of the infused solution, we infused $1.0 \mu \mathrm{l}$ of an MRI contrast agent, gadolinium (5 nmol; Magnevist; Fig. $1 C$ ), according to the procedure described by Wilke et al. (2010). The range of diffusion visualized in MRI sections was limited to a diameter of $3 \mathrm{~mm}$ at $60 \mathrm{~min}$ after infusion, in agreement with previous gadolinium imaging in our laboratory (Dybdal et al., 2012) and others (Asthagiri et al., 2011). This extent of diffusion also matches that observed by Yoshida et al. (1991) using isotopic labeling to monitor the spread of bicuculline methyl chloride.

Site specificity controls. To control for the effects of a potential BIC leakage along the cannula track dorsal to the target site or into the ventricular area, we included control infusions of BIC into the superficial SC, medial pulvinar, and lateral ventricle dorsal to the SC.

Behavioral evaluation and statistical analysis. Baseline behaviors were assessed before every drug infusion. Video recordings were made of freely moving animals in an observation cage $(61 \times 74 \times 76 \mathrm{~cm})$. Videotapes were analyzed by two independent observers (one blind with respect to the treatment) using the software Observer (Noldus). Inter-observer reliability was controlled by comparing results of video segments scored by both observers, which in this case was $45 \%$ of all video-records (interobserver reliability: mean Pearson's $r=0.96, p<0.0001$; no statistical difference between the means $p=0.41$ ). Video-records were analyzed in 15 min segments (bins); two segments were obtained per baseline ( $0-15$ and $15-30 \mathrm{~min})$ and four segments per infusion $(0-15,15-30,30-45$, and 45-60 min). Behaviors were coded as either states (duration of time in seconds per $15 \mathrm{~min}$ bin; cowering) or events (number of occurrences per $15 \mathrm{~min}$ bin; vocalizations, escape-like behavior, attack of objects). Cowering was coded as a state in which the animal withdrew to the peripheries of the cage, remaining crouched or recoiled with gaze directed upward. Vocalization was coded as any sound/call emitted from the animal; escape-like behavior as a sudden movement/startle; attack of objects as biting, hitting, or throwing objects such as toys and/or rattling cage bars.

Because no within-session or between-session differences were observed for baseline or saline infusions, a single baseline value for each animal and each behavior was obtained by averaging across all available $15 \mathrm{~min}$ baseline/saline segments. The mean number of baselines per animal was 13 (range 5-24). The number of drug infusions per animal ranged between 2 and 13. Individual drug infusions varied in the dose and location within DLSC as described in Results.

Since the number of infusions, doses, and sites varied within and between animals, we identified for each animal one infusion that gave the strongest effect during the first 15 min bin ("maximum early response"). The "maximum early response" was defined as the greatest number of vocalizations or escape-like behaviors and the longest duration of cowering evoked in the first bin. Choosing the first bin after infusion assured us that the behavior was evoked from the site of infusion and not due to drug spread. The locations of the sites that evoked the maximum early response in each animal are shown in Figure $1 A$.

Statistical analyses were performed using SPSS, SAS, and GraphPad Prism. Paired Wilcoxon Sign Rank Test was applied to comparisons between baseline and drug treatment for each behavior. Nonparametric Skillings-Mack Test (Skillings and Mack, 1981) for repeated measures was used for time course comparisons, followed by Dunn's post hoc comparisons. $p$-values $<0.05$ were considered statistically significant.

\section{Results}

\section{Effect of BIC in DLSC}

BIC infusion in DLSC evoked behaviors that were not present during baseline or after saline infusions: cowering, escape-like behavior, high-pitch vocalization, and attack of objects. Cowering was typically accompanied by orienting of the head and eyes to the contralateral upper visual field with a slight bending of the trunk ipsilaterally. Escape-like behavior typically occurred as a sudden burst of running or jumping. The high-pitched vocalizations that occurred following BIC in DLSC were distinct from the lower pitch cooing sounds exhibited during baseline conditions. With the exception of attack of objects in one animal (late onset in GW), all behaviors that appeared during an experimental session were evident within the first 3 min of the observation period, reached a peak within the first $30 \mathrm{~min}$, and gradually declined thereafter.

Figure 2, $A 1-C 1$, shows the individual values and group means for the defense-like behaviors measured during the first 
15 min of the experimental session in which maximum early responses were obtained for each animal. All nine animals showed cowering, starting within the first $2 \mathrm{~min}$ (Fig. $2 A 1 ; \mathrm{W}=45, p<$ 0.005). For two animals (ST and OL), cowering was the only response evoked. The remaining seven animals also showed escape-like responses (Fig. 2B1; $\mathrm{W}=28, p<0.05)$ and increased vocalization (Fig. $2 \mathrm{Cl}$; $\mathrm{W}=28, n=7, p<$ $0.05)$. All these behaviors increased significantly compared with baseline.

Figure 2, A2-C2, shows the time course of behaviors over the $1 \mathrm{~h}$ observation period. For cowering $(A 2)$, escapelike behavior (B2), and vocalizations (C2), there was a significant main effect of time $(\mathrm{SM}=9.93, p<0.03 ; \mathrm{SM}=20.97, p<$ 0.0004 ; $\mathrm{SM}=16.04, p<0.003$, respectively). Post hoc comparisons revealed that the duration/count of all three behaviors was significantly elevated above baseline for the $0-15,15-30$, and $30-45 \mathrm{~min}$ bins (all $p$ values $<0.05$ ).

The behaviors observed in each animal were consistent across different infusion sites in DLSC. Two animals, DE and GW, each had four BIC infusions between 7 and $14 \mathrm{nmol}$, and, in all cases, cowering, escape-like behavior, and vocalization were evoked; in addition, GW exhibited attack behavior after these treatments. Attack behaviors directed toward objects were observed in three males after BIC doses between 7 and $14 \mathrm{nmol}$ (GW, DA, and $\mathrm{OK}$ ).

For all effective infusions, at least one of the defense-like behaviors listed above appeared within the first $2 \mathrm{~min}$ of observation (range $0-98 \mathrm{~s}$, mean $=17 \mathrm{~s}$ ); in some cases, the defense-like responses appeared during the infusion, before the animal being placed in the observation cage. Additionally, contralaterally directed eye movements consistently accompanied these early defense-like responses.

\section{Dose dependence}

Infusion of a dose of $2.5 \mathrm{nmol} \mathrm{BIC}$ in DLSC $(7 \times$ in $B R, 1 \times$ in $\mathrm{ZH})$ did not evoke defense-like behaviors. The lowest dose effective for producing defense-like behaviors was $4.6 \mathrm{nmol}$ (Table 1). Therefore, we defined this dose as the effective threshold. There were a total of 38 infusions within DLSC, 30 of which were above threshold (4.6-14 nmol); defense-like behaviors were manifest after $83 \%$ ( 25 of 30 ) of these infusions (Table 1).

Within the dose range of 2.5-14 nmol, the effects of BIC were dose-dependent. In three animals $(\mathrm{ZH}, \mathrm{GW}, \mathrm{DE})$, two different doses were tested in a single site (the same site which evoked the maximum early response), allowing different doses to be compared within a given site in the same animal. In addition, in one

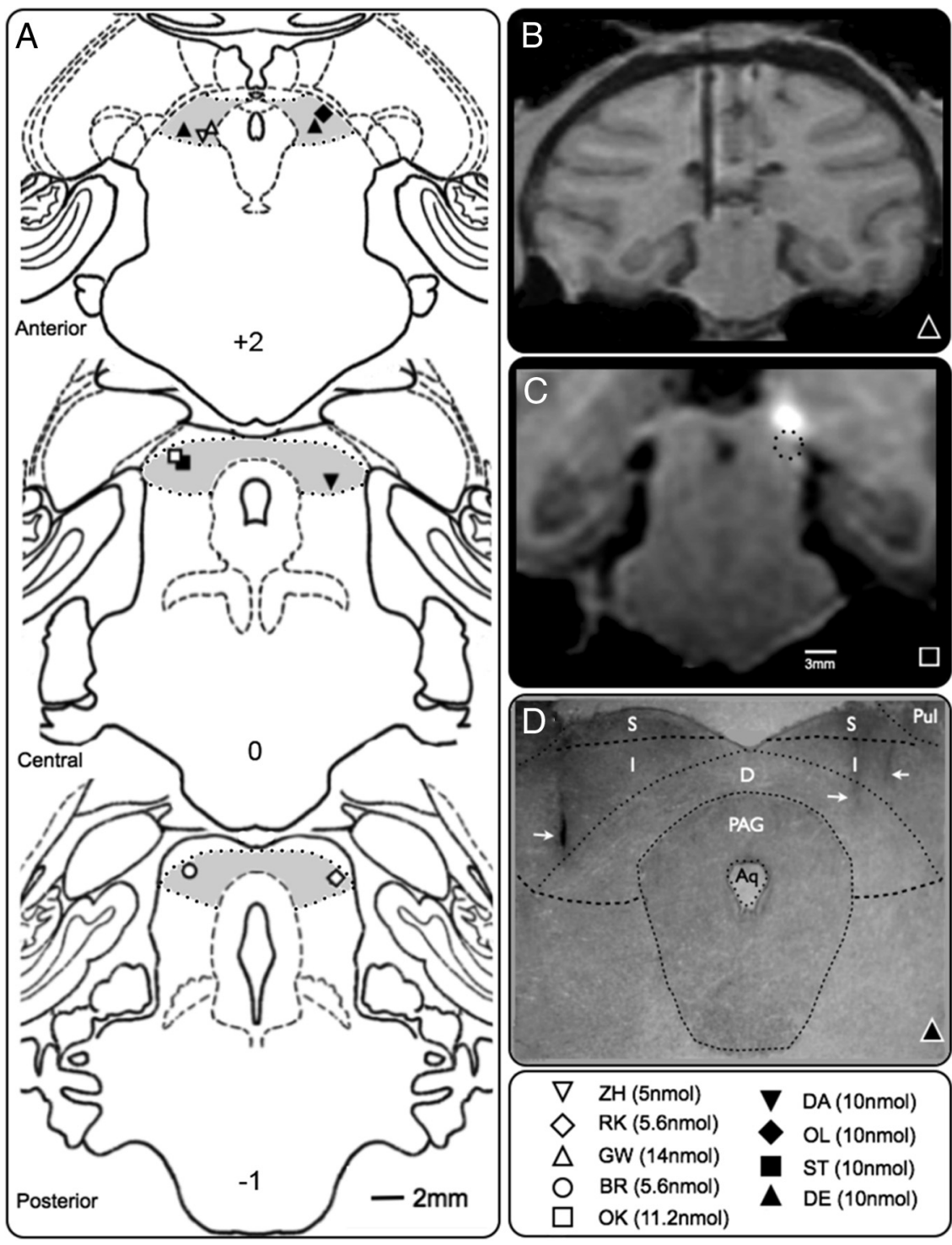

Figure 1. Localization of infusion sites. A, Coronal planes from a standard monkey atlas showing DLSC (shaded area) at anterior $(+2 \mathrm{~mm})$, central $(0 \mathrm{~mm})$, and posterior $(-1 \mathrm{~mm})$ levels; the numbers are distances from interaural plane. Symbols show the location of the infusion sites, from which the maximum early response was obtained for each animal; the BIC dose is in parentheses. The sites for $\mathrm{GW}$ and ZH also represent the sites used for dose-response (Fig. 3). For animal DE, two sites are plotted: the site in the left hemisphere evoked the maximum early response; both the sites in the left and the right hemisphere were used for doseresponse (Fig. 3). The sites were reconstructed from MRI for all animals and confirmed by histology for four (ZH, RK, GW, and DE). $\boldsymbol{B}$, Representative MR image (animal DE) showing electrodes placed in DLSC. Image corresponds to the anterior plane in $\boldsymbol{A}$. C, MR image (animal ST) following infusion of gadolinium $(5 \mathrm{~nm}, 1 \mu \mathrm{l})$ into the superficial layers of SC. White area shows hypersignal (3 $\mathrm{mm}$ in diameter) indicating diffusion of the $1 \mu \mathrm{l}$ volume $60 \mathrm{~min}$ after infusion. BIC infusion in the same site did not evoke defense-like behaviors. The dashed area outlines an area surrounding the effective infusion site placed $3 \mathrm{~mm}$ ventral to the gadolinium infusion site (center-to-center). BIC infused in this site in DLSC evoked defense-like behaviors. D, Photomicrograph of Nissl-stained coronal section through DLSC of animal DE at a level corresponding to that shown in $\boldsymbol{B}$. The arrows point to the tips of cannula tracks. Left track corresponds to the electrode placement in $\boldsymbol{B}$. On the right, the medial track was used for dose-response and is plotted in $A$. Aq, Cerebral aqueduct; Pul, pulvinar; $S$, superficial layers of superior colliculus; $I$, intermediate layers of superior colliculus; $D$, deep layers of superior colliculus.

animal (DE), two doses of BIC were tested in an additional site in the opposite hemisphere. As shown in Figure 3, in animal $\mathrm{ZH}$, no defense-like responses were evoked with $2.5 \mathrm{nmol}$, but $5 \mathrm{nmol}$ evoked the maximum early response. In animal GW, $5 \mathrm{nmol}$ evoked a weaker response than $14 \mathrm{nmol}$; GW also exhibited attack behavior but only at the higher dose (data not shown). In animal DE, $7.5 \mathrm{nmol}$ evoked a weaker response than $10 \mathrm{nmol}$ in both hemispheres. 

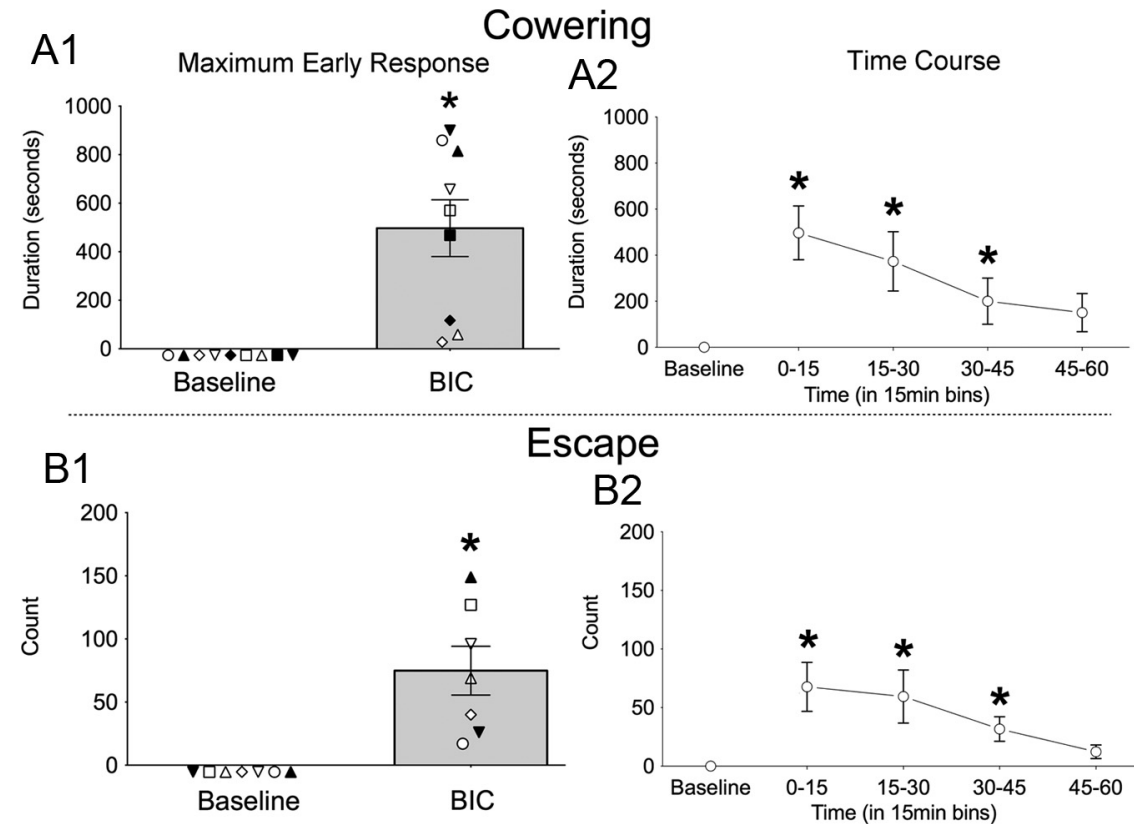

Escape
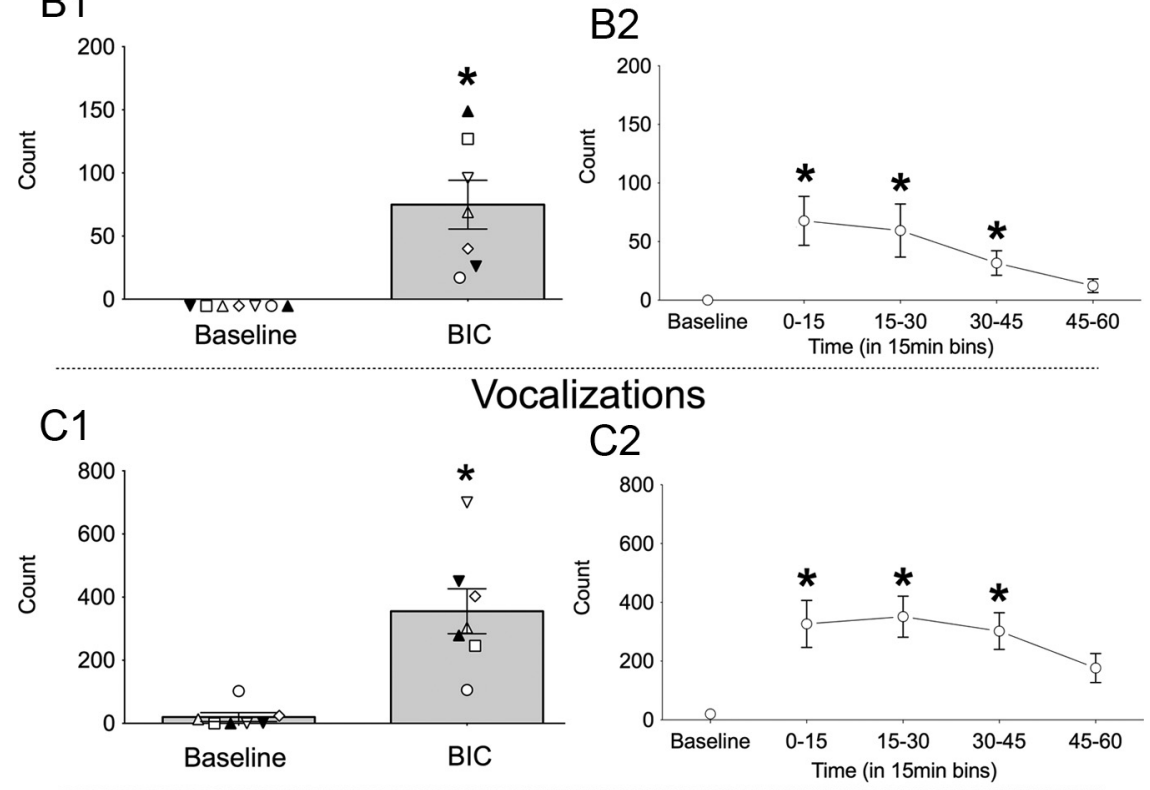

Vocalizations

C2

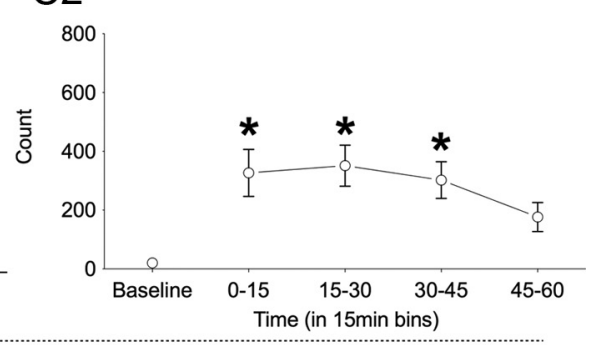

$\underline{\text { Cases }}$

$\begin{array}{lllll}-\mathrm{OL} & \triangle \mathrm{DE} & \diamond \mathrm{RK} & \nabla \mathrm{ZH} & \circ \mathrm{BR} \\ \nabla \mathrm{DA} & \text { - } \mathrm{ST} & \triangle \mathrm{GW} & \square \mathrm{OK} & \end{array}$

Figure 2. Defense-like behavioral responses evoked by BIC in DLSC during the maximum early response (A1-C 1$)$ and over the 60 min observation period (A2-C2). A1-C1, Data show the mean duration ( \pm SEM) or the mean number (count; \pm SEM) of behaviors during the maximum early response. The individual values for each animal are plotted as symbols that correspond to those plotted in Figure 1. For each behavior, only those animals that exhibited the behavior are included in the graphs (OL and ST are not included in $\mathbf{B 2}, \mathbf{B}$ and $\mathbf{C}$, $\mathbf{C}$ as they exhibited only cowering). $\mathbf{A 2}-\mathbf{C}$, Data show the time course for each of the evoked behaviors (mean \pm SEM). All animals plotted in the bar graphs $(\boldsymbol{A} 1-C 1)$ are represented in the time course. However, two animals (DE and GW) are included only for the $0-15$ and $15-30$ min bins because their data could be analyzed only for the first 30 min. ${ }^{*} p<0.05$ compared with baseline.

\section{Site specificity}

Behavioral responses evoked from different sites within DLSC were consistent within and across animals. Infusions into lateral, central, or medial regions of DLSC elicited comparable defenselike behavioral responses.

There were 17 infusions of BIC (in six animals) that served as controls for potential BIC leakage up the cannula track or into the ventricular system. These infusion sites, located in the lateral ventricle, medial pulvinar, and the superficial layers of SC, did not evoke defense-like behaviors. Figure $1 C$ presents an MR image (animal ST) showing a diameter of infusion of $3 \mathrm{~mm}$, as indicated by the area of hypersignal, 60 min after gadolinium infusion into the superficial layers of SC. BIC infusion into this site did not evoke defense-like behaviors, consistent with the diffusion not reaching DLSC (Fig. 1C). In contrast, infusion into a site in DLSC, $3 \mathrm{~mm}$ ventral to the gadolinium infusion site, evoked defense-like behaviors.

\section{Histological verification of infusion site localization}

Cannula placement as determined from thionin-stained brain sections of four animals consistently agreed with placement determined from MRI scans (Fig. $1 B, C$ ), consistent with our prior reports (Wellman et al., 2005; Dybdal et al., 2012).

\section{Discussion}

Our results are the first documentation of defense-like behaviors evoked by activation of DLSC in the non-human primate. Activation of DLSC by the focal blockade of GABAergic inhibition evoked cowering, escape-like responses, high-pitch vocalizations, and attack of objects. These findings were unexpected in the context of the theoretical perspective presented by Dean et al. (1989) that emphasized a preferential role of primate DLSC for approach responses rather than defensive responses. Our findings indicate that the function of DLSC as a substrate for responding to threats is conserved across species.

Activation of DLSC produced defenselike responses that were both passive (i.e., cowering) and active (i.e., escape-like behavior, attack of objects), as well as an increase in defensive vocalization. For a given animal, the behavioral responses evoked from different sites within DLSC were consistent across infusions, suggesting that the various defense-like behaviors do not have independent site specificity. Across animals, the most consistently evoked behavior was cowering (all animals), followed by vocalization and escape-like behaviors (seven of nine animals); attack of objects was observed in only three of nine animals, all males. The cowering and escape-like behaviors resembled defense-like responses evoked from the rat following DLSC stimulation (Dean et al., 1989, Schenberg et al., 2005). Moreover, attack of objects in the monkey appears to be analogous to the biting of objects described in the rat (Redgrave et al., 1981). The vocalization we observed in the monkeys, which may correspond to fear-related ultrasonic vocalization in the rat (Vivian and Miczek, 1999), resembled the screams, high-pitched barks, and shrieks that have been described as submissive and defensive responses to threats in monkeys (Hauser, 1993).

All behaviors that we evoked from DLSC occurred with rapid onset (within the first $2 \mathrm{~min}$ ) and often during the infusion period. This provides important verification that all of the responses obtained result from drug action within DLSC. This is further reinforced by the fact that the latency to onset of the defense-like responses did not differ as a function of mediolateral or dorsoventral position within DLSC. The highly circumscribed drug spread indicated by gadolinium (Fig. 1C) together with the observations that behavioral responses did not differ as a func- 
Table 1. Summary of BIC injections in DLSC above threshold

\begin{tabular}{llll}
\hline Animal & $\begin{array}{l}\text { Number of injections in } \\
\text { DLSC above threshold }\end{array}$ & $\begin{array}{l}\text { NusC above threshold } \\
\text { DLS } \\
\text { resulting in defense-like } \\
\text { response }\end{array}$ & $\begin{array}{c}\text { Effective dose } \\
\text { range (nmol) }\end{array}$ \\
\hline BR & 2 & 2 & $5.6-7$ \\
ZH & 1 & 1 & 5 \\
GW & 7 & 7 & $4.6-14$ \\
RK & 6 & 3 & $5.6-7$ \\
OK & 1 & 1 & 11.2 \\
ST & 4 & 2 & 10 \\
DE & 5 & 5 & $5-10$ \\
DA & 2 & 2 & 10 \\
OL & 2 & 2 & 10 \\
Summary & 30 & 25 & $4.6-14$ \\
\hline
\end{tabular}

${ }^{{ }^{T}}$ Threshold $=4.6 \mathrm{nmol} \mathrm{BIC}$.

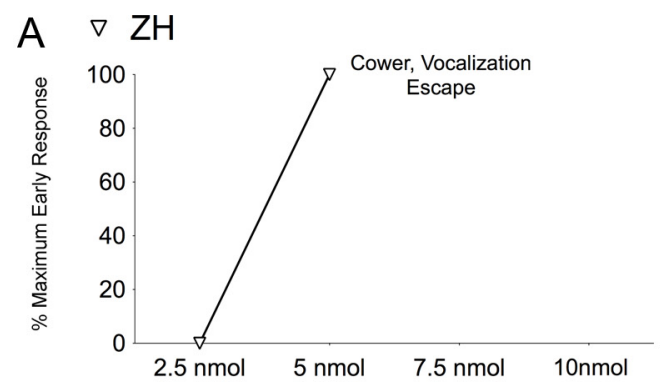

\section{B $\triangle \mathrm{GW}$}

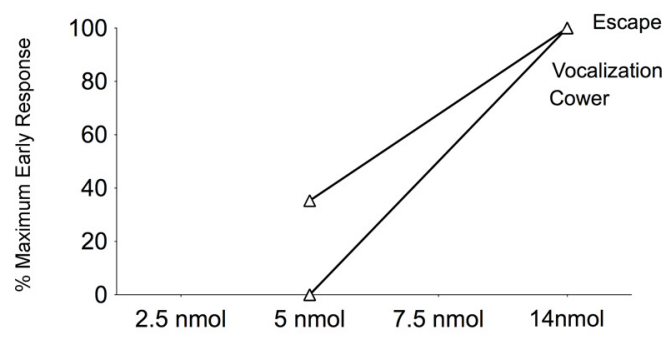

\section{$C \triangle D E$}

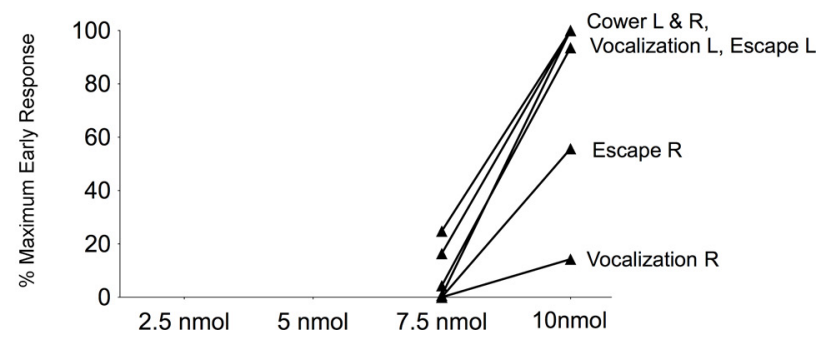

Figure 3. Dose dependence of defense-like behaviors evoked from DLSC. Defense-like responses are shown as percentage of the maximum early response depicted in Figure 2, A1-C1 (i.e., for each behavior, $100 \%$ equals the value for the maximum early response, $0 \%$ equals no response). $\boldsymbol{A}, \boldsymbol{B}$, In animals $Z \mathrm{H}$ and $\mathrm{GW}$, two doses ( $2.5 \mathrm{vs} 5 \mathrm{nmol}$ and $5 \mathrm{vs} 14 \mathrm{nmol}$, respectively), one infusion each, were used in the same site as shown in Figure 2. C, In Animal DE, two infusions per dose ( $7.5 \mathrm{vs} 10 \mathrm{nmol}$ ) were used, one from right (R) and one from left DLSC (L, same site as that for Fig. 2).

tion of location of infusion site within DLSC, indicate that spread of drug to adjacent brain areas does not significantly contribute to any of the behavioral responses we have observed.

Infusions of BIC into sites within both medial and lateral DLSC evoked cowering in all animals. This topography contrasts with the medial-lateral segregation observed in the rat, where defense-like behaviors (i.e., shying away from a perceived threat) were preferentially evoked from medial DLSC (Dean et al., 1989). The topography in the rat has been explained by the fact that medial DLSC preferentially responds to stimuli in the upper visual field, which is the principal location of predator approach for rats. Although DLSC in monkey has similar visuotopic mapping (i.e., upper and lower visual fields map onto medial and lateral DLSC, respectively) (Cynader and Berman, 1972), the response to DLSC activation in the present study did not appear to be segregated as had been described in the rat, perhaps because monkeys respond to threats from both above and below (Comoli et al., 2012).

In rats, the medial-lateral functional segregation within DLSC is aligned with distinct descending projections that mediate approach (pursuit) responses and defense (escape) responses (Dean et al., 1989). Approach responses are mediated via the crossed tecto-reticulo-spinal tract (predorsal bundle) (Dean et al., 1989) and defense responses are mediated via the uncrossed projections from DLSC to the cuneiform nucleus, midbrain and pontine reticular formation (Dean et al., 1989, their Fig. 2). The descending anatomical projections from DLSC as described in the rat are also present in the monkey (Huerta and Harting, 1984; Sparks, 1986; Guitton, 1991; Gandhi and Katnani, 2011). However, whereas the pursuit-related gaze shifting (eye movements) and associated orienting responses (Hikosaka and Wurtz, 1985) are relayed via the crossed predorsal bundle (Gandhi and Katnani, 2011), it remains to be determined whether the uncrossed projections mediate the defense-like behaviors we have observed. The cowering behavior following activation of DLSC often involved an ipsilaterally directed contraction of the trunk concurrent with a contralaterally directed eye gaze and head turning, suggesting that our treatment engages both crossed and uncrossed descending projections from DLSC. In addition, it is likely that the affective component of the behaviors evoked from DLSC depends upon ascending projections that reach the amygdala and other limbic structures (Day-Brown et al., 2010; Tamietto and de Gelder, 2010). This possibility is supported by the finding that lesions of DLSC in the monkey (Maior et al., 2011) impaired emotional processing of threatening stimuli in a manner similar to that observed after amygdala lesions (Meunier et al., 1999).

In rats, DLSC, along with PAG, IC, and the mesencephalic reticular formation comprise a ponto-mesencephalic network for defense-like behaviors (Brandão et al., 1994; Zhao and Davis, 2004). Progressively increasing electrical stimulation in each of these structures induces aversive responses (arousal, freezing, and escape) accompanied by changes in heart rate and blood pressure. The behavioral repertoire evoked from each of these structures in the rat is a function of the topography of stimulation and the projections between them (Brandão et al., 1999). For example, PAG, which has reciprocal connections with DLSC, is thought to modulate responses evoked from DLSC (Schenberg et al., 2005; e.g., Bittencourt et al., 2005). The ability to evoke defensive vocalization from subregions of PAG in the monkey (Dujardin and Jürgens, 2005) raises the prospect that interconnections between DLSC and PAG (Mantyh, 1982, 1983) may also regulate defensive behaviors in primates. The ability of DLSC to trigger a highly integrated pattern of affective and motor responses fits with the concept proposed by Denny-Brown (1962) that the SC serves as a driving force in the mesencephalic network subserving reactivity to the environment.

Our results demonstrate that DLSC is an important substrate for defense-like behavior in the non-human primate, making it a 
likely substrate for this type of behavior in humans. Under normal conditions, this system may serve as a rapid detection and response mechanism for avoiding sudden and threatening stimuli. When disinhibited, as we have achieved with GABA receptor blockade, the defense-like responses emerged without provocation, resembling symptoms seen in post-traumatic stress disorder (PTSD) (Vieweg et al., 2006). The extent to which the behaviors evoked from DLSC in the non-human primate may be modified by environmental context, previous experience, or conditioning is unclear. However, such modifications have been shown for defense-like behaviors evoked from the midbrain tegmentum of the rat (Davis, 1986; Schenberg et al., 2005) and merit further exploration. DLSC circuitry may be particularly relevant for modeling and modifying hyper-responsive defensive reactions, such as occur in combat-related PTSD.

\section{References}

Anderson EJ, Rees G (2011) Neural correlates of spatial orienting in the human superior colliculus. J Neurophysiol 106:2273-2284. CrossRef Medline

Asthagiri AR, Walbridge S, Heiss JD, Lonser RR (2011) Effect of concentration on the accuracy of convective imaging distribution of a gadoliniumbased surrogate tracer. J Neurosurg 115:467-473. CrossRef Medline

Bittencourt AS, Nakamura-Palacios EM, Mauad H, Tufik S, Schenberg LC (2005) Organization of electrically and chemically evoked defensive behaviors within the deeper collicular layers as compared to the periaqueductal gray matter of the rat. Neuroscience 133:873-892. CrossRef Medline

Brandão ML, Cardoso SH, Melo LL, Motta V, Coimbra NC (1994) Neural substrate of defensive behavior in the midbrain tectum. Neurosci Biobehav Rev 18:339-346. CrossRef Medline

Brandão ML, Anseloni VZ, Pandóssio JE, De Araújo JE, Castilho VM (1999) Neurochemical mechanisms of the defensive behavior in the dorsal midbrain. Neurosci Biobehav Rev 23:863-875. CrossRef Medline

Comoli E, Das Neves Favaro P, Vautrelle N, Leriche M, Overton PG, Redgrave P (2012) Segregated anatomical input to sub-regions of the rodent superior colliculus associated with approach and defense. Front Neuroanat 6:9. Medline

Cowie RJ, Robinson DL (1994) Subcortical contributions to head movements in macaques. I. Contrasting effects of electrical stimulation of a medial pontomedullary region and the superior colliculus. J Neurophysiol 72:2648-2664. Medline

Cynader M, Berman N (1972) Receptive-field organization of monkey superior colliculus. J Neurophysiol 35:187-201. Medline

Davis M (1986) Pharmacological and anatomical analysis of fear conditioning using the fear-potentiated startle paradigm. Behav Neurosci 100:814824. CrossRef Medline

Day-Brown JD, Wei H, Chomsung RD, Petry HM, Bickford ME (2010) Pulvinar projections to the striatum and amygdala in the tree shrew. Front Neuroanat 4:143, 2010 Nov 15. Medline

Dean P, Redgrave P, Westby GW (1989) Event or emergency? Two response systems in the mammalian superior colliculus. Trends Neurosci 12:137-147. CrossRef Medline

Denny-Brown D (1962) The midbrain and motor integration. Proc R Soc Med 55:527-538. Medline

Dujardin E, Jürgens U (2005) Afferents of vocalization-controlling periaqueductal regions in the squirrel monkey. Brain Res 1034:114-131. CrossRef Medline

Dybdal D, Forcelli PA, Dubach M, Oppedisano M, Holmes A, Malkova L, Gale K (2012) Topography of dyskinesias and torticollis evoked by inhibition of substantia nigra pars reticulata. Mov Disord. Advance online publication. Retrieved Nov. 24, 2012. doi:10.1002/mds.25215. CrossRef

Gandhi NJ, Katnani HA (2011) Motor functions of the superior colliculus. Annu Rev Neurosci 2011;34:205-231. CrossRef

Guitton D (1991) Control of saccadic eye movements by the superior colliculus and basal ganglia. In: Eye movements (Carpenter RHS, ed), pp 244-274. Boca Raton: CRC.

Hauser M (1993) The evolution of non-human primate vocalizations: effects of phylogeny, body weight, and social context. Am Naturalist 142: 528-542. CrossRef
Hikosaka O, Wurtz RH (1985) Modification of saccadic eye movements by GABA-related substances. I. Effect of muscimol and bicuculline in monkey superior colliculus. J Neurophysiol 53:266-291. Medline

Holmes AL, Forcelli PA, DesJardin JT, Decker AL, Teferra M, West EA, Malkova L, Gale K (2012) Superior colliculus mediates cervical dystonia evoked by inhibition of the substantia nigra pars reticulata. J Neurosci 32:13326-13332. CrossRef Medline

Huerta MF, Harting JK (1984) The mammalian superior colliculus: studies of its morphology and connections. In: Comparative neurology of the optic tectum (Vanegas H, ed), pp 687-773. New York: Plenum.

Maior RS, Hori E, Barros M, Teixeira DS, Tavares MC, Ono T, Nishijo H, Tomaz C (2011) Superior colliculus lesions impair threat responsiveness in infant capuchin monkeys. Neurosci Lett 504:257-260. CrossRef Medline

Mantyh PW (1982) The ascending input to the midbrain periaqueductal gray of the primate. J Comp Neurol 211:50-64. CrossRef Medline

Mantyh PW (1983) Connections of midbrain periaqueductal gray in the monkey. II. Descending efferent projections. J Neurophysiol 49:582-594, 1983 Mar. Medline

McHaffie JG, Stein BE (1982) Eye movements evoked by electrical stimulation in the superior colliculus of rats and hamsters. Brain Res 247:243-253.

Meunier M, Bachevalier J, Murray EA, Málková L, Mishkin M (1999) Effects of aspiration versus neurotoxic lesions of the amygdala on emotional responses in monkeys. Eur J Neurosci 11:4403-4418. CrossRef Medline

Redgrave P, Dean P, Souki W, Lewis G (1981) Gnawing and changes in reactivity produced by microinjections of picrotoxin into the superior colliculus of rats. Psychopharmacology (Berl) 75:198-203. CrossRef

Sahibzada N, Dean P, Redgrave P (1986) Movements resembling orientation or avoidance elicited by electrical stimulation of the superior colliculus in rats. J Neurosci 6:723-733. Medline

Schenberg LC, Póvoa RMF, Costa ALP, Caldellas AV, Tufik S, Bittencourt AS (2005) Functional specializations within the tectum defense systems of the rat. Neurosci Biobehav Rev 29:1279-1298. CrossRef Medline

Skillings JH, Mack GA (1981) On the use of Friedman-type statistic in balanced and unbalanced block designs. Technometrics 23:171-177. CrossRef

Sparks DL (1986) Translation of sensory signals into commands for control of saccadic eye movements: role of primate superior colliculus. Physiol Rev 1986 66:118-171.

Stein BE, Stanford TR, Rowland BA (2009) The neural basis of multisensory integration in the midbrain: its organization and maturation. Hear Res 258:4-15. CrossRef Medline

Tamietto M, de Gelder B (2010) Neural bases of the non-conscious perception of emotional signals. Nat Rev Neurosci 11:697-709. CrossRef Medline

Vieweg WVR, Julius DA, Fernandez A, Beatty-Brooks M, Hettema JM, Pandurangi AK (2006) Posttraumatic stress disorder: clinical features, pathophysiology, and treatment. Am J Med 119:383-390. CrossRef Medline

Vivian JA, Miczek KA (1999) Interactions between social stress and morphine in the periaqueductal gray: effects on affective vocal and reflexive pain responses in rats. Psychopharmacology (Berl) 146:153-161. CrossRef

Wellman LL, Gale K, Malkova L (2005) GABAA-mediated inhibition of basolateral amygdala blocks reward devaluation in macaques. J Neurosci 25:4577-4586. CrossRef Medline

West EA, DesJardin JT, Gale K, Malkova L (2011) Transient inactivation of orbitofrontal cortex blocks reinforcer devaluation in macaques. J Neurosci 31:15128-15135. CrossRef Medline

Wilke M, Turchi J, Smith K, Mishkin M, Leopold DA (2010) Pulvinar inactivation disrupts selection of movement plans. J Neurosci 30:8650-8659. CrossRef Medline

Wurtz RH, Albano JE (1980) Visual-motor function of the primate superior colliculus. Annu Rev Neurosci 3:189-226. CrossRef Medline

Yoshida M, Nagatsuka Y, Muramatsu S, Niijima K (1991) Differential roles of the caudate nucleus and putamen in motor behavior of the cat as investigated by local injection of GABA antagonists. Neurosci Res 10:3451. CrossRef Medline

Zhao Z, Davis M (2004) Fear-potentiated startle in rats is mediated by neurons in the deep layers of the superior colliculus/deep mesencephalic nucleus of the rostral midbrain through the glutamate non-NMDA receptors. J Neurosci 24:10326-10334. CrossRef Medline 